\title{
Clinical Features and Outcome of Saline Hydrostatic Reduction in Patients with Intussusception in a Tertiary Care Centre
}

\author{
Binu M K ${ }^{1}$, Maneesha U R $\mathbf{R}^{1}$, Shinaz Sadiq ${ }^{1}$ \\ ${ }^{1}$ Assistant Professor, Department of Paediatric Surgery, Government Medical College, Trivandrum, Kerala, \\ India. \\ Corresponding Author: Binu M K
}

DOI: https://doi.org/10.52403/ijrr.20220134

\begin{abstract}
Background: Intussusception is one of the most frequent causes of acute bowel obstruction in infants and toddlers. Abdominal sonogram is highly specific, accurate and is the first line diagnostic modality. The primary treatment options are non-operative hydrostatic or pneumatic reduction. In our institution, we use normal saline for reduction of intussusception under ultrasound guidance (USGR). The aim of the study is to analyse the clinical pattern and treatment outcome of intussusception.

Methodology: Retrospective analysis of all cases admitted with intussusception in our department during 2014-2018 was done.

Results: 785 cases (527 males: 258 females) with a mean age of 25 months and median of 16 months had abdominal pain (92.5\%), vomiting $(59 \%)$ and blood in stools $(32 \%)$ as the predominant symptoms. $710 / 785$ cases $(90.4 \%)$ underwent successful USGR and 75/785 of the failed cases underwent surgery. Age group $<12$ months, presence of blood in stools irrespective of its duration and prolonged vomiting $>48$ hours were found to be significant factors for failed USGR. Vomiting and blood in stools were found to be significantly higher in children $<12$ months of age $(\mathrm{p}<0.005)$, whereas pathological lead points were more frequent in children $>3$ years of age.
\end{abstract}

Conclusion: With a high success rate and no significant complication rate, USGR is an effective non-operative treatment modality for intussusception. Age group $<12$ months, prolonged vomiting and presence of blood in stool were found to affect the success rate of hydrostatic reduction.

Keywords: Intussusception, saline, ultrasound, hydrostatic reduction

\section{INTRODUCTION}

Intussusception is the invagination of one part of the intestine into another and is one of the most frequent causes of acute bowel obstruction in infants and toddlers with peak incidence between 3 months to 3 years. [1] The classic presentation of intussusception in a young child is with intermittent abdominal pain, vomiting, red currant jelly stool and a palpable mass. ${ }^{[2]}$ Ultrasound is primary diagnostic investigation which is highly specific and accurate. Presently, treatment modalities have changed from operative to nonoperative treatment which has resulted in decreased mortality and morbidity. ${ }^{[3]}$ Non operative treatment modalities include ultrasound guided hydrostatic reduction (USGR), barium hydrostatic reduction under fluoroscopy and pneumatic reduction. Delayed diagnosis and intervention is a significant contributing factor for increased morbidity and mortality. ${ }^{[4,5]}$ In our institution, we use USGR with normal saline as the primary treatment. The aim of the study is to analyse the present clinical pattern of intussusception with respect to patient demographics, symptomatology and 
treatment outcomes (non-operative/ operative) in a tertiary care centre.

\section{METHODOLOGY}

\section{Study design}

This is a retrospective record based descriptive study

\section{Study setting}

All cases of intussusception admitted in Department of Paediatric Surgery, Government Medical College Thiruvananthapuram during the period from 2014 to 2018.

\section{Study population}

Inclusion criteria: All children up to 12 years of age with the diagnosis of intussusception were included in the study.

Exclusion criteria: Those who presented with features of complications like peritonitis, bowel gangrene or perforation were excluded from the study.

\section{MATERIALS AND METHODS}

Our hospital protocol for management of intussusception starts with initial confirmation of sonographic diagnosis by the radiologist, following which the child is admitted, kept nil per mouth and is hydrated. USGR is performed under sedation using intravenous Midazolam. A $16 \mathrm{~F}$ foley catheter is inserted into rectum and bulb is inflated with $30 \mathrm{ml}$ distilled water. The buttocks are strapped together. The catheter is connected using an intravenous drip-set line to a Normal Saline bag, which is warmed to body temperature and kept at a height of $100 \mathrm{~cm}$ from the pubis of the patient. Saline is allowed to flow freely and no external pressure is applied to the saline bag. The reduction is monitored using ultrasound, available in the department, performed by Paediatric Surgeon. The disappearance of intussusception mass, free flow of saline and filling of terminal ileal bowel loops which resembles honeycomb are taken as end point of successful reduction. Oral feeds are started 6 hours after the procedure and child is discharged after 24 hours. Repeat USG is done only if child is symptomatic. If reduction is unsuccessful or incomplete, a repeat attempt is done after 4 hours. Maximum of 3 such attempts can be done in an otherwise stable child, provided there are no evidence of intussusception or procedure related complications. If there is no movement of intussusceptum during saline reduction, then no further attempts are made. Child is taken up for surgery if reduction is unsuccessful after repeated attempts. If child develops recurrent intussusception, the same procedure is repeated.

The following data were collected patient demographics, details of symptoms (abdominal pain, vomiting and blood in stools), success rates of hydrostatic reduction and operative findings in cases of failed USGR. The data collection and analysis were done with Microsoft Excel and Jamovi v2.0 software. The data underwent t-test and Pearson chi-square test analysis and a $\mathrm{p}$ value $<0.05$ was considered to be statistically significant.

\section{RESULTS}

A total of 785 patients were studied during the period 2014 to 2018 . There were 258 females and 527 males (male to female ratio of $2.04: 1$ ). The mean age was 25 months and median age was 16 months. The youngest patient was 1 month old and the oldest was 149 months old. Majority of the children were less than 3 years of age (Table 1). The most common symptom was abdominal pain (726 [92.48\%]) followed by vomiting (464 [59.11\%]) and bleeding per rectum (252 [32.10\%]). None of them presented with features of peritonitis or perforation and hence all were subjected to hydrostatic reduction.

Of the 785 patients, successful saline reduction was achieved in 710 patients (90.4\%). (Table 2) and the 75 cases (9.6\%) with failed hydrostatic reduction underwent surgery. In the surgical group, 60/75 (80\%) had ileocolic (IC) intussusception, 14/75 $(18.67 \%)$ had ileo-ileocolic intussusception 
and 1 had jejuno-jejunal intussusception following nephrectomy for Wilms tumour. A Pathological Lead Point (PLP) was found in 12 operated cases (16\%). (Table 2). Meckel's diverticulum was the most common PLP, seen in 9 cases. 2 cases were due to tumour of ileo-caecal junction which later turned out to be lymphoma. There was 1 case of polyp in ileum causing intussusception in a child with PeutzJeghers syndrome (PJS). Intestine was gangrenous in 6 cases of which 4 were having Meckel's diverticulum.

Table 1

\begin{tabular}{|l|l|l|l|}
\hline & All cases & Successful hydrostatic reduction & Failed hydrostatic reduction \\
\hline Mean age & 25 & 25 & 20 \\
\hline Standard Deviation & 25 & 24.4 & 29.8 \\
\hline Median & 16 & 17 & 7 \\
\hline Range & $1-149$ & $1-149$ & $2-132$ \\
\hline & & & \\
\hline Males & $527(67 \%)$ & 472 & 55 \\
\hline Females & $258(33 \%)$ & 238 & 20 \\
\hline & & & \\
\hline Age groups & & & 57 \\
\hline$<12$ months of age & 322 & 265 & 18 \\
\hline$>12$ months of age & 463 & 445 & \\
\hline & & & 59 \\
\hline$<3$ years of age & 614 & 555 & 16 \\
\hline$>3$ years of age & 171 & 155 & \\
\hline
\end{tabular}

Table 2

\begin{tabular}{|c|c|c|}
\hline \multicolumn{3}{|l|}{ Total cases $=785$} \\
\hline \multirow[t]{3}{*}{$\begin{array}{lr}\text { USG } & \text { reduction } \\
\text { successful }=710(90.4 \%)\end{array}$} & \multicolumn{2}{|c|}{$\begin{array}{l}\text { USG reduction failed }=75(9.6 \%)- \\
\text { underwent surgery }\end{array}$} \\
\hline & $\begin{array}{l}\text { No PLP }= \\
63 / 75\end{array}$ & $\mathrm{PLP}=12 / 75$ \\
\hline & & $\begin{array}{l}\text { Meckel's } \\
\text { diverticulum = } \\
\text { Tumor }=2 \\
\text { Polyp }=1\end{array}$ \\
\hline
\end{tabular}

Analysis

Age, gender \& age groups:

Age $(p=0.18)$ and gender $(p=0.23)$

were not significant factors affecting the outcome of hydrostatic reduction. However, when children $<12$ months of age were compared with those older than 12 months of age, the failure rate of hydrostatic reduction was significantly higher in the former group $(p<0.00001)$. But no significant difference was found when children less than 3 years and more than 3 years of age were compared $(p=0.92)$ (Table3).

Table 3

\begin{tabular}{|c|c|c|c|c|}
\hline Age group & All cases & Successful hydrostatic reduction & Failed hydrostatic reduction & p value \\
\hline$<12$ months & 322 & $265(82.30 \%)$ & $57(17.70 \%)$ & \multirow[t]{2}{*}{$<0.00001$} \\
\hline$>12$ Months & 463 & $445(96.11 \%)$ & $18(3.89 \%)$ & \\
\hline$<3$ Years & 614 & $555(90.39 \%)$ & $59(9.61 \%)$ & \multirow[t]{2}{*}{0.92} \\
\hline$>3$ Years & 171 & $155(90.64 \%)$ & $16(9.36 \%)$ & \\
\hline
\end{tabular}

\section{Symptomatology:}

We found no statistical difference in the failure of hydrostatic reduction when patients with more than 48 hours of overall symptoms were compared with those having less than 48 hours of symptoms $(\mathrm{p}=0.7)$ (Table 4)

Table 4

\begin{tabular}{|l|l|l|l|l|}
\hline & $>48$ hours of symptoms & $<\mathbf{4 8}$ hours of symptoms & total & p value \\
\hline Failed hydrostatic reduction & 20 & 55 & 75 & 0.7 \\
\hline Successful hydrostatic reduction & 175 & 535 & 710 & \\
\hline Total & 195 & 590 & 785 & \\
\hline
\end{tabular}

\section{Abdominal pain:}

$726 / 785$ cases had abdominal pain with $662 / 710$ in the successful hydrostatic reduction group and $64 / 75$ in the failed reduction group having this symptom. Abdominal pain and its duration were not a significant factor in the outcome of hydrostatic reduction $(\mathrm{p}=0.46)$ (Table7) 
Binu M K et.al. Clinical features and outcome of saline hydrostatic reduction in patients with intussusception in a tertiary care centre.

\section{Vomiting:}

464/785 patients had vomiting, with 351 in the successful hydrostatic reduction group and 41 in the failed reduction group. Persistent vomiting of more than 48 hours was a significant factor for failed reduction $(\mathrm{p}=0.005)($ Table 7$)$. Age group of less than 12 months was found to be a significant factor for occurrence of vomiting as a symptom in intussusception $(\mathrm{p}=0.005)$ (Table 5)

Table 5

\begin{tabular}{|l|l|l|l|l|}
\hline & $<\mathbf{1 2}$ months of age & $\mathbf{> 1 2}$ months of age & Total cases & p value \\
\hline Vomiting & 209 & 255 & 464 & 0.005 \\
\hline No Vomiting & 113 & 208 & 321 & \\
\hline Total & 322 & 463 & 785 & \\
\hline
\end{tabular}

\section{Blood in stools:}

Presence of blood in stools (BIS) was a significant factor for failed hydrostatic reduction $(\mathrm{p}<0.00001)$, irrespective of its duration (table 7). Age group of less than 12 months was a significant factor for occurrence of blood in stools $(\mathrm{p}<0.00001)$, with 179/ $252(71 \%)$ cases of BIS occurring in this age group (table 6), whereas 73/252 (29\%) cases occurred in children $>12$ months. 179 out of $322(56 \%)$ children $<12$ months had BIS, whereas $143 / 322(44 \%)$ of children $>12$ months had no BIS. This correlates well with the reduced success rate in children $<12$ months.

Table 6

\begin{tabular}{|l|l|l|l|l|}
\hline & $<\mathbf{1 2}$ months of age & $>\mathbf{1 2}$ months of age & Total & p value \\
\hline Blood in stools present & 179 & 71 & 250 & $<0.00001$ \\
\hline No blood in stools & 143 & 392 & 535 & \\
\hline Total & 322 & 463 & 785 & \\
\hline
\end{tabular}

Table 7

\begin{tabular}{|c|c|c|c|c|c|}
\hline Symptom & Total & Successful & Failed & p value & \\
\hline \multicolumn{6}{|l|}{ Abdominal pain (AP) } \\
\hline $\mathrm{AP}<48$ & 549 & $503(91.62 \%)$ & $46(8.38 \%)$ & \multirow[t]{2}{*}{0.46} & \multirow[t]{2}{*}{ Not significant } \\
\hline $\mathrm{AP}>48$ & 177 & $159(89.83 \%)$ & $18(10.17 \%)$ & & \\
\hline Total cases with abdominal pain & 726 & $662(91.18 \%)$ & $64(8.82 \%)$ & & \\
\hline No Abdominal pain & 59 & $48(81.36 \%)$ & $11(18.64 \%)$ & & \\
\hline \multicolumn{6}{|l|}{ Vomiting } \\
\hline Vomiting $<48 \mathrm{~h}$ & 392 & $351(89.54 \%)$ & $41(10.46 \%)$ & \multirow[t]{2}{*}{0.005} & \multirow[t]{2}{*}{ Significant } \\
\hline Vomiting $>48 \mathrm{~h}$ & 72 & $56(77.78 \%)$ & $16(22.22 \%)$ & & \\
\hline Total Vomiting & 464 & $407(87.72 \%)$ & $57(12.28 \%)$ & & \\
\hline No Vomiting & 321 & $303(94.39 \%)$ & $18(5.61 \%)$ & & \\
\hline \multicolumn{6}{|l|}{ Blood in stool (BIS) } \\
\hline BIS $<48$ & 236 & $191(80.93 \%)$ & $45(19.07 \%)$ & \multirow[t]{2}{*}{0.24} & \multirow[t]{2}{*}{ Not significant } \\
\hline BIS $>48$ & 16 & $11(68.75 \%)$ & $5(31.25 \%)$ & & \\
\hline Total BIS & 252 & $202(80.16 \%)$ & $50(19.84 \%)$ & \multirow[t]{2}{*}{$<0.00001$} & \multirow[t]{2}{*}{ Significant } \\
\hline No BIS & 533 & $508(95.31 \%)$ & $25(4.69 \%)$ & & \\
\hline
\end{tabular}

\section{Analysis of pathological lead point (PLP) with age:}

Mean age was higher in children with PLP (50.28), when compared with children with no PLP (14.55). Older age was significant factor for occurrence of PLP $(\mathrm{p}=0.029)$. PLP was present in 5 out of 56 cases $(8.93 \%)$ in $<12$ months age and 7 out of 19 cases $(36.84 \%)$ in $>12$ months age. PLP was present in 6 out of 60 cases $(10 \%)$ in $<3$ years and 6 out of 15 cases $(40 \%)$ in $>3$ years $(\mathrm{p} 0.005)$ (Table 8$)$.

\begin{tabular}{|c|c|c|c|}
\hline \multicolumn{4}{|c|}{ Table 8} \\
\hline & PLP & no PLP & p value \\
\hline $\mathrm{n}$ & 12 & 63 & \\
\hline \multicolumn{4}{|l|}{ Age } \\
\hline Mean age & 50.28 & 14.55 & 0.029 \\
\hline SD & 49.30 & 20.46 & \\
\hline Median & 41.50 & 6.9 & \\
\hline Range & $2-132$ & $2-102$ & \\
\hline \multicolumn{4}{|l|}{ Sex } \\
\hline Males & 7 & 47 & \\
\hline Females & 5 & 16 & \\
\hline \multicolumn{4}{|c|}{ Age Group } \\
\hline$<12 \mathrm{~m}$ & 5 & 51 & \\
\hline$>12 \mathrm{~m}$ & 7 & 12 & \\
\hline$<3 y$ & 6 & 54 & 0.005 \\
\hline$>3 y$ & 6 & 9 & \\
\hline
\end{tabular}




\section{DISCUSSION}

Intussusception is a leading cause of acute abdomen in children. Its incidence is 1-4 per 2000 infants with $90 \%$ cases in children less than 3 years. ${ }^{[1]}$ In our study, majority - 78\% (614/785) were less than 3 years of age, with a peak incidence in the $<12$ months age group - $41 \%(322 / 785)$. Children mostly present with abdominal pain which manifest as irritability or incessant cry (93\%), vomiting (85\%)and blood in stool $(37 \%){ }^{[2]}$ In our study, the most common symptom was abdominal pain with an incidence of $92.48 \%$, followed by vomiting $(59.11 \%)$ and blood in stool $(32.10 \%)$. In our study, incidence of blood in stool was higher in the age group $<12$ months compared to those $>12$ months.

Prompt diagnosis is necessary to avoid complications like intestinal gangrene, perforation, sepsis and shock. Ultrasonogram (USG) is the most commonly used diagnostic modality. It has a sensitivity of $98-100 \%$ and specificity of 88-100\%. ${ }^{[6]}$ Previously all cases of intussusception were managed by laparotomy. In 1876, Harald Hirschsprung made the first attempt at hydrostatic reduction of intussusception using water. Kim et al first described hydrostatic reduction of intussusception under USG guidance. ${ }^{[7]}$ Now a days, intussusception is managed by minimally invasive procedures like hydrostatic (fluid) or pneumatic (air) reduction. ${ }^{[8,9]}$ Both procedures are widely used and superiority of each over the other is debated. ${ }^{[10,11]}$ We use hydrostatic reduction using normal saline under ultrasound guidance.

The one major advantage of this method is that, this procedure can be done by the treating paediatric surgeon, without any help from the radiologist. In our institution, we have been practising the same for the last 25 years. Surgical management is required only in those with failed hydrostatic reduction or those presenting with complication like intestinal perforation and gangrene. The advantages of USG guided hydrostatic reduction (USGR) include its simplicity and easy availability, no radiation exposure, less complications and minimal hospital stay. Hydrostatic reduction is reported to have a success rate of $90-95 \% .^{[12]}$ Our success rate is found to be $90.4 \%$.

A number of factors affect the success of hydrostatic reduction. The factors that are commonly studied are age, gender, history of vomiting, rectal bleeding, and abdominal pain, length of the invaginated segment measured on USG, bowel wall thickness, duration of symptoms, small bowel obstruction etc. ${ }^{[13-15]}$ Stein et al. reported that long duration of symptoms was a predictor of failure of pneumatic reduction. ${ }^{[16]}$ Rectal bleeding is an indicator of edema and circulatory impairment. Presence of rectal bleeding is found to reduce success rate of hydrostatic reduction. ${ }^{[17]}$ Similarly, in our study, blood in stools was a significant factor for failure of USGR. Also vomiting > 48hrs duration was a significant factor contributing to failure of USGR. Khorana et al. also reported that the success of the procedure was not affected within the first $48 \mathrm{~h}$ after the onset of symptoms, but the success rate started to decrease from the third day after the onset of the symptoms. ${ }^{[18]}$ In our study we couldn't find any statistically significant association of overall duration of symptoms with successful reduction, except for vomiting where children with duration $>48 \mathrm{hrs}$ had increased failure rate $(22.22 \%$ vs $10.46 \%)$.

Majority of the cases of intussusception are idiopathic. The incidence of intussusception caused by a PLP in an infant or child ranges from $1.5 \%$ to $12,{ }^{[1]}$ with majority occurring in older children. Meckel's diverticulum is the most common PLP found in intussusception, ${ }^{[19,20]}$ which was also the case in our study $(62.5 \%)$. Other lead points include lymphoma, polyps, duplication cyst and bowel wall tumours like lipoma, hamartoma, haemangioma and lymphangioma. A lead point can be diagnosed by ultrasound in only less than a 
third of the cases. ${ }^{[21]}$ There's a high chance of failure of USGR in cases with PLP and most of the lead points are identified only during surgery for such failed non-operative cases.

\section{CONCLUSION}

Intussusception should always be suspected in infants and toddlers with colicky pain and vomiting. Palpation of the intussusceptum mass in an already distressed toddler is difficult. Blood in stools is a relatively less common and late symptom and its presence has a higher chance for failure of non-operative methods. With easy availability of sonogram, these cases can be diagnosed earlier and nonoperative treatment with the highly effective ultrasound guided saline reduction can be done prior to the occurrence of complications.

\section{Acknowledgement: None}

\section{Conflict of Interest: None}

\section{Source of Funding: None}

\section{Ethical Approval: Approved}

\section{REFERENCES}

1. Columbani PM, Scholz S, Coran AG, Adzick NS, Krummel TM, Laberge JM, Shamberger RC, Caldamone AA. Intussusception. In: Pediatric Surgery. Philadelphia: Saunders; 2012. p. 1093-110.

2. Mandeville K, Chien M, Willyerd FA, Mandell G, Hostetler MA, Bulloch B. Intussusception: Clinical Presentations and Imaging Characteristics. Pediatric Emergency Care. 2012 Sep;28(9):842-4.

3. Archibong AE, Usoro IN, Ikpi E, Inyang A. Peadiatric intussusception in Calabar, Nigeria. E Af Med Jrnl. 2001 Jan 1;78(1): 19-21.

4. Ekenze S O, Mgbor S O. Childhood intussusception: The implications of delayed presentation. Afr J Paediatr Surg. 2011;8(1): $15-8$.

5. Chan K, Chan J, Peh W, Chan K, Tam P. Endotoxemia associated with intussusception and its diagnostic and surgical interventions. Ped Surgery Int. 2002 Dec;18(8):685-8.

6. Krishnakumar, Hameed S. Ultrasound guided hydrostatic reduction in the management of intussusception. Indian $\mathbf{J}$ Pediatr. 2006 Mar;73(3):217-20.

7. Kim, Young Goo, Choi, B. I., Yeon, K. M., et al. Diagnosis and treatment of childhood intussusception using rea-time ultrasonography and saline enema: preliminary report. Journal of the Korean Society of Medical Ultrasound. 1982;1(1):66-70.

8. Justice FA, Auldist AW, Bines JE. Intussusception: Trends in clinical presentation and management. $\mathbf{J}$ Gastroenterol Hepatol. 2006 May;21(5):842-6.

9. Kaiser AD, Applegate KE, Ladd AP. Current success in the treatment of intussusception in children. Surgery. 2007 Oct;142(4):469-77.

10. Jenke AC, Klaaen-Mielke R, Zilbauer M, Heininger $U$, Trampisch $\mathrm{H}$, Wirth $\mathrm{S}$. Intussusception: Incidence and TreatmentInsights From the Nationwide German Surveillance. Journal of Pediatric Gastroenterology \& Nutrition. 2011 Apr; 52(4):446-51.

11. Sanchez TR, Doskocil B, Stein-Wexler R. Nonsurgical Management of Childhood Intussusception: Retrospective Comparison Between Sonographic and Fluoroscopic Guidance. Journal of Ultrasound in Medicine. 2015 Jan;34(1):59-63.

12. Bai YZ, Qu RB, Wang GD, Zhang KR, Li $Y$, Huang $Y$, et al. Ultrasound-guided hydrostatic reduction of intussusceptions by saline enema: a review of 5218 cases in 17 years. The American Journal of Surgery. 2006 Sep 1;192(3):273-5.

13. Fike FB, Mortellaro VE, Holcomb GW, St. Peter SD. Predictors of failed enema reduction in childhood intussusception. Journal of Pediatric Surgery. 2012 May;47(5):925-7.

14. Fallon SC, Lopez ME, Zhang W, Brandt ML, Wesson DE, Lee TC, et al. Risk factors for surgery in pediatric intussusception in the era of pneumatic reduction. Journal of Pediatric Surgery. 2013 May;48(5):1032-6.

15. Karadağ ÇA, Abbasoğlu L, Sever N, Kalyoncu MK, Yildız A, Akın M, et al. Ultrasound-guided hydrostatic reduction of intussusception with saline: Safe and 
Binu M K et.al. Clinical features and outcome of saline hydrostatic reduction in patients with intussusception in a tertiary care centre.

effective. Journal of Pediatric Surgery. 2015 Sep;50(9):1563-5.

16. Stein M, Alton DJ, Daneman A. Pneumatic reduction of intussusception: 5-year experience. Radiology. 1992 Jun;183(3): $681-4$.

17. Avci V, Agengin K, Bilici S. Ultrasound Guided Reduction of Intussusception with Saline and Evaluating the Factors Affecting the Success of the Procedure. Iran J Pediatr. $2018 \mathrm{Feb} 19 ; 28(1)$.

18. Khorana J, Singhavejsakul J, Ukarapol N, Laohapensang M, Siriwongmongkol J, Patumanond J. Prognostic indicators for failed nonsurgical reduction of intussusception. TCRM. 2016 Aug;Volume 12:1231-7.

19. Sagar J, Kumar V, Shah DK. Meckel's diverticulum: a systematic review. Journal of the Royal Society of Medicine. 2006 Oct 1;99(10):501-5.
20. Ghritlaharey RK. Management of Intussusceptions Secondary to Pathological Lead Points in Infants and Children. Annals of the National Academy of Medical Sciences (India). 2021 Jan;57(01):53-7.

21. Fiegel H, Gfroerer S, Rolle U. Systematic review shows that pathological lead points are important and frequent in intussusception and are not limited to infants. Acta Paediatr. 2016 Nov;105(11): 1275-9.

How to cite this article: Binu M K, Maneesha U $\mathrm{R}$, Shinaz Sadiq. Clinical features and outcome of saline hydrostatic reduction in patients with intussusception in a tertiary care centre. International Journal of Research and Review. 2022; 9(1): 291-297. DOI: https://doi.org/10. 52403/ijrr.20220134 